\title{
Microstructure and physicochemical characteristics of modified taro starch after annealing, autoclaving-cooling and heat moisture treatment
}

\author{
${ }^{1,2}$ Setiarto, R.H.B., ${ }^{1}$ Kusumaningrum, H.D., ${ }^{1}$ Jenie, B.S.L., ${ }^{2 *}$ Khusniati, T., \\ ${ }^{2}$ Widhyastuti, N. and ${ }^{2}$ Ramadhani, I. \\ ${ }^{1}$ Departement of Food Science and Technology, Faculty of Agricultural Technology, Bogor Agriculture \\ University (IPB University), Bogor 16680, Indonesia \\ ${ }^{2}$ Microbiology Division, Research Center for Biology, Indonesian Institute of Sciences (LIPI) Main Street \\ Jakarta-Bogor Km 46, Cibinong Science Center, Cibinong, Bogor, 16911 West Java, Indonesia
}

Article history:

Received: 19 February 2020

Received in revised form: 20 March 2020

Accepted: 22 March 2020

Available Online: 15 April 2020

\section{Keywords:}

Annealing,

Autoclaving-cooling,

Heat moisture treatment,

Microstructure and

physicochemical

characteristics,

Modified taro starch

DOI:

https://doi.org/10.26656/fr.2017.4(4).079

\begin{abstract}
This study investigated the effects of annealing, autoclaving-cooling and heat moisture treatment on the microstructure and physicochemical characteristics of taro starch. The taro starch was treated by the annealing process $\left(24 \mathrm{hrs}, 50^{\circ} \mathrm{C}\right)$, the heat moisture treatment (HMT) (moisture $\left.25 \%, 3 \mathrm{hrs}, 110^{\circ} \mathrm{C}\right)$, and the autoclaving $\left(15 \mathrm{mins}, 121^{\circ} \mathrm{C}\right)$ cooling $\left(24 \mathrm{hrs}, 4^{\circ} \mathrm{C}\right)$ with 1 and 2 cycles. The results show that the autoclaving-cooling 2 cycles (AC-2C) changed the microstructure of taro starch into a very compact and dense structure because of formed double helix bound that cannot be hydrolyzed by pancreatic enzymes so it can be converted became resistant starch as the prebiotic source. Pasting properties analysis showed that $\mathrm{AC}-2 \mathrm{C}$ improved shear stress resistance, heat resistance and low retrogradation modified taro starch (MTS). The AC-2C treatment increased water binding capacity $(73.84 \%)$, solubility $(44.58 \%)$, and swelling power $(16.71 \%)$ of MTS. The water-binding capacity had a positive correlation with solubility and swelling power. The AC-2C treatment increased amylose content $(27.40 \%)$ and decreased reducing sugar level $(6.36 \%)$ of MTS, so it can encourage the formation of resistant starch to improve the prebiotic properties of taro starch. Modified taro starch AC-2C is the best compared to HMT and annealing based on microstructure and physicochemical characteristics.
\end{abstract}

\section{Introduction}

Colocasia esculenta known as taro was one of the tubers from the Araceae family that is of the most widely cultivated in tropical areas of Southeast Asia, South and West Africa (Aboubakar et al., 2009). The taro starch content is high $(70-80 \%)$, so it can be applied as raw materials for food processing (Arici et al., 2016). Taro starch is highly digestible and it has a unique small size of granules (3-5 $\mu \mathrm{m})$ (Kaushal et al., 2012). Native taro starch has limited use in food application as it has many weaknesses such as narrow peak viscosity range, low process tolerance, worse shear stress resistance, thermal decomposition, high retrogradation and cooked starches will form a weak, cohesive and rubbery paste ( $\mathrm{Yu}$ et al., 2018). These weaknesses increase the interest of many researchers to modify taro starch so its physicochemical characteristics could be improved (Sharlina et al., 2017). Taro starch modification techniques could be carried out by its physical, chemical or enzymatic properties (Hazarika and Sit, 2016). Some physical modification techniques could improve the functional properties of taro starch including the autoclaving-cooling cycle, heat moisture treatment (HMT) and annealing.

The autoclaving-cooling process was the physical modification to convert the original taro starch into the more resistant starch type III (RS3) (Dundar and Gocmen, 2013). The repeated process of autoclavingcooling may cause in the formation of the retrograded and crystallized amylose fraction (Ashwar et al., 2016). The amylose fraction bound to other amylose fractions via hydrogen bonds to form a double helix structure (Simsek and E1, 2015). The structure of the double helix bound to the other double helix structures form crystals, therefore there was a recrystallization process of the amylose fraction, called RS3 formation process (Shah et al., 2016).

The HMT process was conducted using low moisture content $(<35 \%)$ and heated at the temperature that exceeds the gelatinization temperature $\left(80-130^{\circ} \mathrm{C}\right)$ for 15 
mins to $16 \mathrm{hrs}$ (Cheng et al., 2019). The amylose recrystallization occurred during the cooling process. The HMT method changed the characteristics of starch gelatinization, which increased the tendency of retrograded starch (Zheng et al., 2018). The association of amylose-amylose chain in the amorphous area can also be increased by the HMT process, resulted in the granule material compaction (Anderson et al., 2002). In addition, the amylose-amylopectin chain could also be enhanced by the HMT process.

Annealing was a modification of starch achieved by heating below the gelatinization temperature with the water content addition (Xu et al., 2018). Modification of starch with annealing tends to change the functional properties and digestibility of starch without changing the structure of starch granules (Wang et al., 2017). Annealing treatment caused the gelatinization temperature rise and the starch digestibility to fall (Wang et al., 2018). Setiarto et al. (2018) report that fermentation and two cycles of autoclaving-cooling can improve prebiotic properties of modified taro flour and it successfully increased the resistant starch (RS) content by 2.8 -fold compared to the control treatment. This study is aimed to determine the microstructure and physicochemical characteristics of modified taro starch by implementing annealing, HMT and autoclavingcooling treatments.

\section{Materials and methods}

\subsection{Materials}

The main raw material used in this study was the Bogor Taro of Pandan (Colocasia esculenta) with eight months harvest age, from Cijeruk Bogor West Java, Indonesia.

\subsection{Taro starch extraction}

Taro starch extraction was performed by applying the technique from Airul et al. (2014) with a few modifications. Taro tuber was peeled, washed, and soaked in the mixture of $1 \% \mathrm{NaCl}$ (3:4) for an hour to remove oxalate crystals. It was then shredded and mixed with distilled water $(3: 1)$ for one minute using a blender (Phillips, Netherland). Double fold cotton cloth was utilized to filter the taro pulp. The obtained taro pulp filtrate was settled overnight to let the starch sink at the base of the beaker glass. Taro pulp was centrifuged with High Speed Centrifuge (Kubota, Japan) at $5000 \mathrm{rpm}$ for 10 mins to obtain taro starch. Distilled water was used to clean the taro starch three times to remove the supernatant. After that, it was oven-dried at $50^{\circ} \mathrm{C}$ up to the constant weight. Finally, the dry taro starch was ground using the disk mill (China).

\subsection{Annealing treatment}

The annealing treatment of taro starch was conducted by the technique by Wang et al. (2018). Taro starch of $12 \mathrm{~g}$ was added to $60 \mathrm{~mL}$ of distilled water with the ratio of taro starch: water $(1: 5)(\mathrm{b} / \mathrm{v})$ was placed in a polyethylene bag. The annealing treatment was carried out at $50^{\circ} \mathrm{C}$ for $24 \mathrm{hrs}$ by inserting a polyethylene bag which had been tightly closed into a water bath (Hitachi, Japan). Afterward, the taro starch was freeze dried, crushed and filtered using the 100-mesh sieve. The resulting taro starch from the annealing process was then chilled at $4^{\circ} \mathrm{C}$ prior to further analysis.

\subsection{Heat-moisture treatment}

The taro starch modification using HMT was obtained following Deka and Sit (2016). Forty-five grams of taro starch (dry-based) was placed into a glass container, and distilled water was added to it while stirring until the water content reached $25 \%$. Then, the glass container was sealed, balanced for $48 \mathrm{hrs}$ at room temperature then heated at $110^{\circ} \mathrm{C}, 3 \mathrm{hrs}$ in an electric oven (Shimizu, Japan) for three hrs. The heated modified taro starch was then dried at $40^{\circ} \mathrm{C}$ for overnight, milled and sieved with a 100-mesh sieve.

\subsection{Autoclaving-cooling treatment}

The autoclaving-cooling method of taro starch followed the procedure by Setiarto et al. (2018). The taro starch was added with aquadest at the ratio of 1:2, heated in an autoclave (Hitachi, Japan) at $121^{\circ} \mathrm{C}$ for 15 mins, then chilled in refrigerator at $4^{\circ} \mathrm{C}$ for $24 \mathrm{hrs}$. Thereafter, the treated taro starch was dried $\left(70^{\circ} \mathrm{C}, 16 \mathrm{hrs}\right)$ in an oven (Shimidzu, Japan) until the moisture content reached $12 \%$, and milled using a pin disk mill (Shimidzu, Japan). The starch was sieved to obtain the 100-mesh taro starch. The autoclaving-cooling treatment was also completed with two cycles.

\subsection{Microstructure analysis}

Scanning Electron Microscopy (SEM) analysis was conducted to establish the taro starch microstructure and particle size. The sputter coater (Hitachi E 102 Ion Sputter) which had a $20 \mathrm{~nm}$ thick gold layer with a conductive two-sided carbon band was used to cover the taro starch samples. The visualization of the surface and the cross section of taro starch granules was performed by placing a film on a piece of aluminum taped with double-sided tape then covered with a $20-30 \mathrm{~nm}$ thick of gold layer. An acceleration voltage of $20.0 \mathrm{kV}$ was used to analyze all samples of taro starch granules. The Hitachi S 2400 scanning electron microscope was used to record and analyze the taro starch granules. The taro starch granules were captured with 10000× 
magnification.

\subsection{Analysis pasting properties}

Both the native and the modified starches were analyzed to understand their gelatinization profile and pasting properties implying the technique from Wang et al. (2018) with the Brabender Viscograph (Brabender ${ }^{\circledR}$ $\mathrm{GmbH}$ and Co. KG., Germany) modification. The distilled water $(450 \mathrm{~mL})$ was added to $30 \mathrm{~g}$ of taro starch sample (dry-based) and mixed to result in the homogenous taro starch suspension ( $7 \%$ starch, $b / b)$. The sample was balanced at $50^{\circ} \mathrm{C}$ for 1 min prior to the increasing temperature up to $95^{\circ} \mathrm{C}$ with $6^{\circ} \mathrm{C} / \mathrm{min}$ speed. The sample was then chilled at $50^{\circ} \mathrm{C}$ with $6^{\circ} \mathrm{C} / \mathrm{min}$ speed. These analyses were performed using the Thermocline Software by Brabender ${ }^{\circledR} \mathrm{GmbH}$ and Co. KG. Germany.

\subsection{Analysis of $p H$, water-binding capacity, solubility and swelling power}

A calibrated $\mathrm{pH}$ analyzer (Thermo Scientific Orion 5 -Star from the USA) was utilized to understand the $\mathrm{pH}$ value of the MTS. MTS of $5 \mathrm{~g}$ was mixed with the distilled water $(20 \mathrm{~mL})$ and then homogenized by a magnetic stirrer for five mins according to the method from Airul et al. (2014) to analyze the $\mathrm{pH}$ value.

Moreover, Airul et al. (2014) methods were also implemented to understand the water-binding capacity of the MTS. The mixture of dried taro starch and distilled water ( $1 \mathrm{~g}$ and $15 \mathrm{~mL}$, respectively) were shaken for an hour. The mixture was then centrifuged at high speed (3000 rpm) for 10 mins using the Kubota centrifuge, Japan.

Furthermore, the other properties of MTS such as its solubility as well as its swelling power were gathered using the modified technique from Jiang et al. (2012). The sample of dried taro starch $(0.1 \mathrm{~g})$ was immersed with distilled water $(10 \mathrm{~mL})$ in the vial, mixed using the magnetic stirrer for $30 \mathrm{mins}$, and heated gradually from $65,75,85$ up to $95^{\circ} \mathrm{C}$ for an hour. The semiliquid or slurry taro starch was chilled afterwards and centrifuged with High Speed Centrifuge (Kubota, Japan) at 3000 rpm, 15 mins. The deposited wet starch was separated from its supernatant, dried for 10 mins, and weighed. The supernatant was finally dried in the oven (Hitachi, Japan). Finally, a drying oven (Hitachi, Japan) was maintained at the temperature of $110^{\circ} \mathrm{C}$ to dry the supernatant until it reached its constant weight.

\subsection{Amylose, amylopectin and reducing sugar content determinations}

Spectrophotometer UV-Vis (Shimadzu UV-1800,
Japan) was used to calculate the contents of amylose, amylopectin and reducing sugar. Both amylose and amylopectin were determined by a method from Sharlina et al. (2017) at $620 \mathrm{~nm}$, while the reducing sugar level was analyzed using a method from Miller (1959) at 540 $\mathrm{nm}$.

\subsection{Statistical analysis}

There were three replications in this experiment, where the statistical analyses were implemented to process the research data. The Duncan statistical test was implied to examine the considerable differences at the level of $p<0.05$ utilizing the SPSS 18.0 statistical software (SPSS, Inc., Chicago, IL, USA).

\section{Results and discussion}

\subsection{Microstructure}

The microstructures of the native, autoclavingcooling cycle, annealing, and heat-moisture treatment (HMT) starches under the SEM microscope were presented in Figures 1 A, B to C, D and E, respectively. The SEM analysis was conducted using 1000x magnification. As shown in Figure 1A various sizes and shapes of granules were found in the native taro starch. The microstructure of granules was irregular polygon, approximately had $5 \mu \mathrm{m}$ granule sizes. This result was almost similar to Deka and Sit (2016) experiment. The autoclaving-cooling taro starch showed a loss in its physical integrity. The irregular shaped particles are dominant as the granular structure transforms into a very compact and dense structure (Figures 1B, 1C). This process likely occurred due to the gelatinization during the autoclaving treatments resulting in swelling, breakup, and degradation of taro starch granule. The taro starch granule particles were expanded and broken because of the entry of water and the heating process at high temperatures. The cooling process caused re-association of hydrogen bonds, hence the amylose structure was trapped in the amylopectin and forms a double helix bond (Deka and Sit, 2016). Modified taro starch by autoclaving-cooling cannot be hydrolyzed by pancreatic enzymes so it can be converted became resistant starch as the prebiotic source. Furthermore, it was also observed that the swelling and agglomeration/fusion of the granules were relatively higher in the autoclavingcooling case compared to the HMT and annealing treatment.

Aggregated and fused starch granules were found in modified starch by HMT and annealing (Figures 1D and $1 \mathrm{E})$, although the starch gelatinization was not observed. Aggregation and fusion of the starch granules were also observed by Hazarika and Sit (2016). HMT and annealing treatments may cause damage of granular 

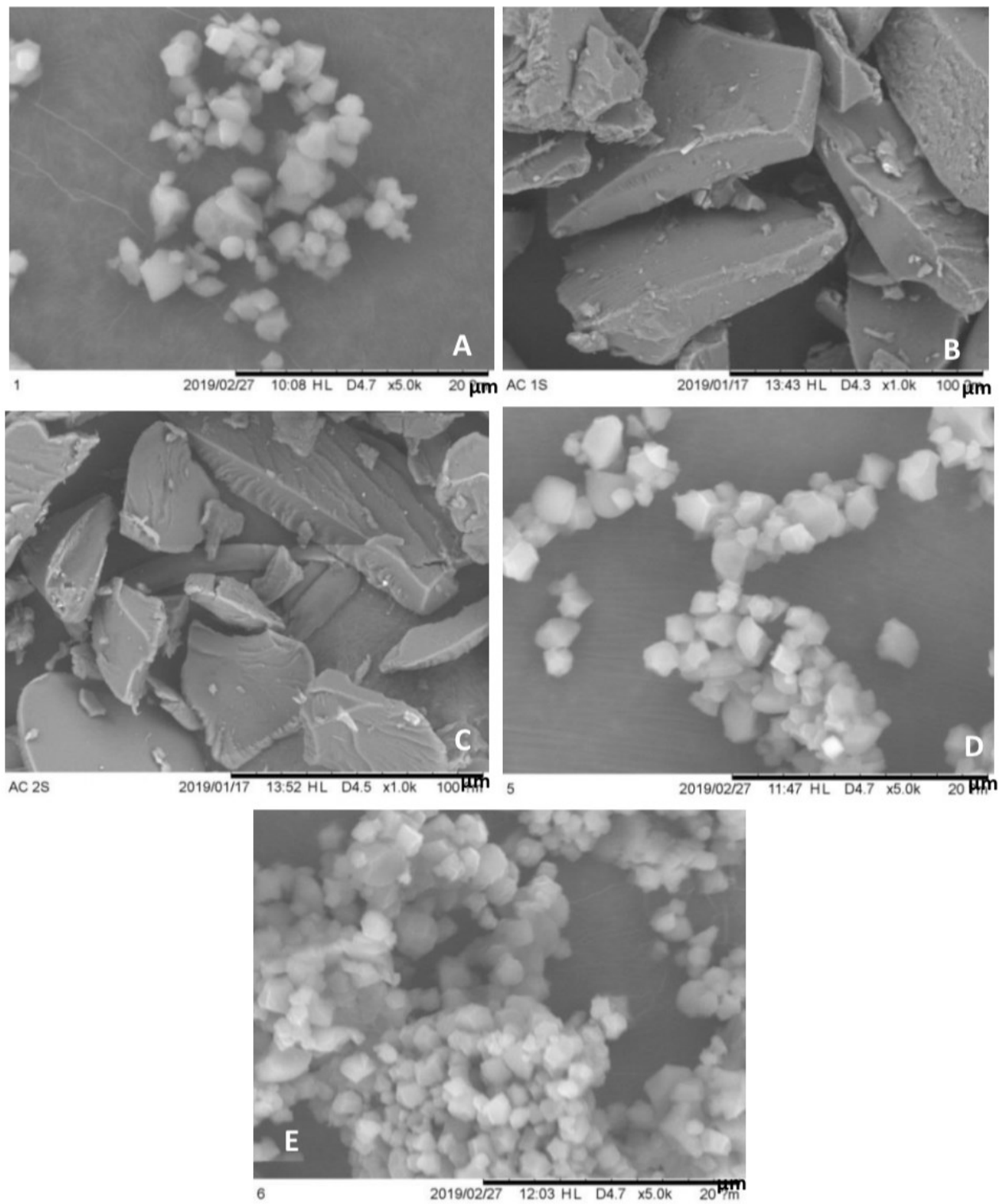

Figure 1. Microstructure of (A) Native taro starch, (B) AC-1C, (C) AC-2C, (D) Annealing, (E) HMT observed in SEM microscope with 1000 magnification.

integrity or the loss of birefringence without gelatinization (Abbas et al., 2010). The annealing treatment at $50^{\circ} \mathrm{C}$ temperature for $24 \mathrm{hrs}$, however, did not show a remarkable change in the taro starch microstructures. The annealing treatment in this study at a temperature of $50^{\circ} \mathrm{C}$ for $24 \mathrm{hrs}$ also did not cause a significant change in the microstructure of taro starch. This can be observed in Figure 1E where there were no double helical bonds or crystallite structure formations during the annealing treatment. The results were in accordance with the research by Wang et al. (2017). Wang et al. (2018) explained that the annealing treatment plays a role in the increase of the amorphous regions ordering in the starch granules through increasing starch chains interaction.

\subsection{Physicochemical characteristics}

\subsubsection{Pasting properties}

Pasting properties of taro starch were determined based on several parameters including gelatinization temperature, gelatinization time, peak time, peak temperature, viscosity peak, viscosity at $93^{\circ} \mathrm{C}$, viscosity at $93^{\circ} \mathrm{C}$ for 20 mins, final viscosity $50^{\circ} \mathrm{C}$ and setback viscosity (Table 1). The autoclaving-cooling cycle treatment reduced the gelatinization temperature of taro starch. Meanwhile, HMT resulted in the increases gelatinization temperature of taro starch while the annealing treatment did not cause a significant change of gelatinization temperature from the native taro starch (Table 1). These results supported the research of Deka and Sit (2016) which modified the starch using microwave treatment and HMT. Simsek and El (2015) reported starch gelatinization temperatures which were indicated by the increase interactions between amyloseamylose, amylose-amylopectin and amylopectinamylopectin, hydrogen bond formation between molecules and formation of larger crystallite structures.

Peak viscosity of taro starch correlated with swelling the powder of taro starch granules during the gelatinization process. Annealing taro starch had the 
Table 1. Pasting properties as gelatinization time and temperature, peak time and temperature and viscosity profile of modified taro starch

\begin{tabular}{|c|c|c|c|c|c|c|c|c|c|}
\hline Treatment & 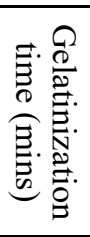 & 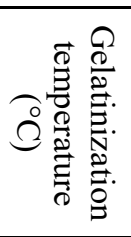 & 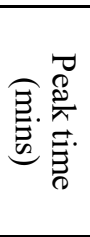 & ○ी & 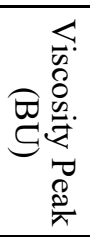 & 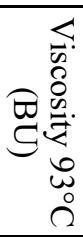 & 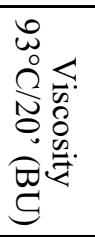 & 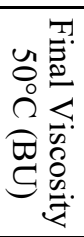 & 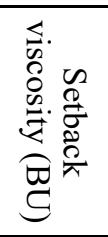 \\
\hline Native Taro starch & 35 & 82.5 & 43 & 94 & 220 & 210 & 210 & 320 & $(+110)$ \\
\hline $\mathrm{AC}-1 \mathrm{C}$ & 24 & 66 & 37 & 85.5 & 170 & 160 & 140 & 180 & $(+40)$ \\
\hline $\mathrm{AC}-2 \mathrm{C}$ & 22 & 66 & 34 & 81 & 100 & 90 & 80 & 120 & $(+40)$ \\
\hline Annealing & 34 & 81 & 42 & 93 & 240 & 240 & 250 & 370 & $(+120)$ \\
\hline HMT & 39 & 88.5 & - & - & - & 50 & 110 & 190 & $(+80)$ \\
\hline
\end{tabular}

highest PV (240 BU) than the other treatments. The annealing treatment in this study increased the viscosity of the pasting properties of taro starch. These results supported the research reported by Wang et al. (2017). The study by Wang et al. (2018) reported that the annealing treatment increased the viscosity of the pasting properties of potato starch. This was associated with a decrease in deformability and an increase in stiffness of annealing starch. The rise of the annealing potato starch viscosity showed that it was highly resistant towards heating and shearing. This occurred as the ordering of amorphous regions in annealing potato starch granules increases.

Starch viscosity at $93^{\circ} \mathrm{C}$ for 20 mins resulted in a heat resistant taro starch. The viscosity of taro starch was constant and then increases during the heating condition at $93{ }^{\circ} \mathrm{C}$ temperature for 20 mins, mainly HMT. It indicated that the HMT taro starch had good heat resistance (Kaushal et al., 2012). The native taro starch, annealing, and $\mathrm{AC}-2 \mathrm{C}$ taro starches also had a good heat resistance (Table 1). However, the HMT taro starch had the highest increase in heat resistance compared to the other treatments (Table 1). The modified taro starch by autoclaving-cooling treatment $(\mathrm{AC}-1 \mathrm{C}$ and $\mathrm{AC}-2 \mathrm{C})$ had the lowest setback viscosity ( $+40 \mathrm{BU})$, which meant that the retrograded rate of this starch was the lowest among others. Annealing taro starch had the highest Setback Viscosity value $(+120 \mathrm{BU})$, indicating that this starch was the most retrograded compared to the other treatments (Table 1). The results of this study supported the research from Deka and Sit (2016) which showed that the taro starch modification using HMT (microwave, autoclave and hot air oven) improved the heat resistance and reduced the retrograded rate. Research on pasting properties in taro flour by Arici et al. (2016) showed a significant effect due to the drying process during flour production. High carbohydrates and low protein levels in the taro flour allowed the water to pass through the starch granules, therefore the swelling power also increased.

\subsubsection{Solubility and swelling power}

High temperature condition increased the solubility and the swelling power of the native and the modified taro starch (MTS) and peaked at $85^{\circ} \mathrm{C}$ to $95^{\circ} \mathrm{C}$ (Table 2). These results supported the previous analyses by Sharlina et al. (2017). Deka and Sit (2016) reported the HMT taro starch solubility at $90^{\circ} \mathrm{C}$ ranged from $9.68 \%$ to $11.73 \%$, with $10.25-13.25(\mathrm{~g} / \mathrm{g})$ swelling power. Sharlina et al. (2017) showed that the Dioscorea pyrifolia tubers starch at $95^{\circ} \mathrm{C}$ had $26.72(\mathrm{~g} / \mathrm{g})$ swelling power and $33.29 \%$ solubility. Moreover, Jiang et al. (2012) also examine swelling power from $D$. opposite, $D$. alata, $D$. nipponica, D. bulbifera, D. septemloba starch at $95^{\circ} \mathrm{C}$ were $12.42,16.92,8.85,12.79,12.14(\mathrm{~g} / \mathrm{g})$ respectively. Meanwhile, the solubility of $D$. opposite, D. alata, $D$. nipponica, D. bulbifera, D. septemloba starch at $95^{\circ} \mathrm{C}$ was $16.27,30.04,11.14,10.46,14.40 \%$ respectively.

The solubility and swelling power improvements after the autoclave treatment were also reported by Dundar and Gocman (2013). The increasing value of the MTS solubility and swelling power occurs due to the weathering process of starch granules during HMT treatment (Dundar and Gocman, 2013). The starches resulted from annealing, HMT and autoclaving-cooling cycle treatments showed significant swelling powers compared to the native taro starch (Table 2). The taro starch solubility was strongly affected by the interaction between water with amylose and amylopectin, and the amylose-amylose and amylose-amylopectin chains bonds (Sharlina et al., 2017). Swelling power was heavily influenced by amylose content, the starch ability to bind water, the level of crystallinity, and the hydrogen bonds (Jiang et al., 2012; Sharlina et al., 2017). Sharlina et al. (2017) report that there was a negative correlation between amylose starch content and swelling power. This occurs as the swelling power capability was limited by the increasing number of amylose in the starch content.

The autoclaving-cooling cycle and HMT changed the starch granules, increased the granule size, therefore 
Table 2. Solubility and swelling power of modified taro starch

\begin{tabular}{|c|c|c|c|c|c|c|c|c|}
\hline \multirow{2}{*}{ Treatment } & \multicolumn{4}{|c|}{ Solubility (\%) } & \multicolumn{4}{|c|}{ Swelling power $(\mathrm{g} / \mathrm{g})$} \\
\hline & $65^{\circ} \mathrm{C}$ & $75^{\circ} \mathrm{C}$ & $85^{\circ} \mathrm{C}$ & $95^{\circ} \mathrm{C}$ & $65^{\circ} \mathrm{C}$ & $75^{\circ} \mathrm{C}$ & $85^{\circ} \mathrm{C}$ & $95^{\circ} \mathrm{C}$ \\
\hline Native taro starch & $2.55 \pm 0.54^{\mathrm{a}}$ & $6.43 \pm 0.44^{\mathrm{b}}$ & $16.16 \pm 0.28^{\mathrm{e}}$ & $42.06 \pm 0.24^{j}$ & $2.06 \pm 0.40^{\mathrm{a}}$ & $13.12 \pm 0.46^{\mathrm{d}}$ & $17.01 \pm 0.34^{\mathrm{e}}$ & $23.75 \pm 0.84^{\mathrm{f}}$ \\
\hline $\mathrm{AC}-1 \mathrm{C}$ & $13.67 \pm 0.43^{d}$ & $16.80 \pm 0.23^{\mathrm{e}}$ & $21.26 \pm 0.35^{\mathrm{f}}$ & $39.99 \pm 0.73^{\mathrm{i}}$ & $12.95 \pm 0.52^{\mathrm{c}}$ & $14.34 \pm 0.82^{\mathrm{d}}$ & $15.59 \pm 0.26^{\mathrm{d}}$ & $24.99 \pm 0.60^{\mathrm{g}}$ \\
\hline $\mathrm{AC}-2 \mathrm{C}$ & $23.02 \pm 0.25^{\mathrm{f}}$ & $23.66 \pm 0.14^{\mathrm{f}}$ & $25.96 \pm 0.65^{\mathrm{g}}$ & $44.58 \pm 0.59^{\mathrm{j}}$ & $12.91 \pm 0.56^{\mathrm{c}}$ & $14.99 \pm 0.64^{\mathrm{d}}$ & $15.24 \pm 0.78^{\mathrm{d}}$ & $16.71 \pm 0.50^{\mathrm{e}}$ \\
\hline Annealing & $2.17 \pm 0.49^{\mathrm{a}}$ & $10.98 \pm 0.67^{\mathrm{c}}$ & $34.07 \pm 0.43^{\mathrm{h}}$ & $37.47 \pm 0.41^{\mathrm{i}}$ & $3.35 \pm 0.38^{\mathrm{a}}$ & $13.55 \pm 0.27^{\mathrm{d}}$ & $16.74 \pm 0.63^{\mathrm{e}}$ & $18.92 \pm 0.71^{\mathrm{e}}$ \\
\hline HMT & $6.81 \pm 0.58^{\mathrm{b}}$ & $10.97 \pm 0.75^{\mathrm{c}}$ & $17.34 \pm 0.29^{\mathrm{e}}$ & $20.46 \pm 0.38^{\mathrm{f}}$ & $8.71 \pm 0.89^{b}$ & $10.19 \pm 0.19^{c}$ & $13.83 \pm 0.74^{\mathrm{d}}$ & $17.89 \pm 0.84^{\mathrm{e}}$ \\
\hline
\end{tabular}

Different superscript letters within a row were significantly different at $\mathrm{p}<0.05$ level

lead to the swelling power improvement. The swelling power of taro starch was also influenced by the structure of amylose and amylopectin, and the magnitude interactions in amorphous and crystalline regions. The crystal structure in the amylopectin molecule played an important role in the gelatinization and the swelling the power of taro starch. The swelling power improvement was affected by the long chain ratio of amylopectin $(\geq 35$ degrees polymerization), lipids and phosphorus (Naidoo et al., 2015). Naidoo et al. (2015) showed that the presence of lipid residues and amylose-lipid complexes can reduce the swelling power of starch.

\subsubsection{Water-binding capacity (WBC), pH, amylose} and amylopectin, reducing sugar content

The autoclaving-cooling cycle (AC-1C, AC-2C) and HMT increased significantly $(\mathrm{p}<0.05)$ the $\mathrm{WBC}$ of taro starch compared to the native taro starch. WBC of modified taro starch $\mathrm{AC}-1 \mathrm{C}, \mathrm{AC}-2 \mathrm{C}$ and $\mathrm{HMT}$ treatments were not significantly different $(\mathrm{p}<0.05)$ (Table 3). Modified taro starches (HMT, AC-1C, and AC -2C) had WBC value between $70.94 \%$ and $73.84 \%$ $(\mathrm{p}<0.05)$ (Table 3). D. pyrifolia starch was $2.45 \% \mathrm{WBC}$ value as reported by Sharlina et al. (2017). Moreover, Jiang et al. (2012) reported the following WBC results: D. opposite $1.41 \%$, D. alata $1.56 \%$, D. nipponica $4.43 \%$, D. bulbifera $2.53 \%$ and D. septemloba $5.57 \%$. This study revealed that the native taro starch and the MTS have higher WBC values compared to D. pyrifolia, D. opposite, D. alata, D. nipponica, D. bulbifera, D. septemloba starches. The WBC (\%) had a positive correlation with solubility (\%) and swelling power. As the MTS bind with water, it got easier to expand and dissolve in water. The WBC (\%) was determined by the number of hydrogen bonds formed between the water molecule and the hydroxyl group in taro starch. In addition, WBC (\%) was also influenced by the degree of starch polymerization and the diversification of the structure of taro starch granules (Kaushal et al., 2012; Sharlina et al., 2017).

Modified taro starches (MTS) had $\mathrm{pH}$ values between 4.5 and 5.04 (Table 3). The HMT taro starch $\mathrm{pH}$ (4.5) was not significantly different from the native taro starch (4.56). On the other hand, the Annealing and the autoclaving-cooling cycling treatments increased the $\mathrm{pH}$ of taro starch. Sharlina et al. (2017) measured the $\mathrm{pH}$ value of $D$. pyrifolia tuber starch of 3.43 , which was relatively lower than the $\mathrm{pH}$ from the native and the MTS taro starches in this study. The heating process of the HMT released the hydrogen ions $\left(\mathrm{H}^{+}\right)$, therefore increased the taro starch $\mathrm{pH}$.

The experiments indicated that the amylose content of native taro starch, HMT, AC-2C taro starch had significant differences $(p<0.05)$. The amylose content of the native taro was $25.33 \%$, the HMT taro starch was $16.01 \%$, and the AC-2C taro starch was $27.40 \%$ (Table 3 ). The amylose value of the HMT taro starch relatively decreased due to the partial gelatinization during the heating process which damaging the amylose structure (Zheng et al., 2018; Cheng et al., 2019). The autoclaving -cooling 2 cycle (AC-2C) caused an increase in amylose levels and a decrease in amylopectin level in taro starch. The amylose content of modified taro starch (AC-2C) revealed an increase significantly compared to native taro starch $(p<0.05)$ (Table 3). The improvement levels of amylose in autoclaving-cooling (AC-2C) taro starch were caused by depolymerization of long chain amylose

Table 3. Water binding capacity (WBC), pH, amylose, amylopectin, reducing sugar content of modified taro starch

\begin{tabular}{cccccc}
\hline Treatment & $\begin{array}{c}\text { Water binding capacity } \\
(\%)\end{array}$ & $\mathrm{pH}$ & $\begin{array}{c}\text { Amylose } \\
(\% \text { dry weight })\end{array}$ & $\begin{array}{c}\text { Amylopectin } \\
(\% \text { dry weight })\end{array}$ & $\begin{array}{c}\text { Reducing sugar } \\
(\% \text { dry weight })\end{array}$ \\
\hline Native taro starch & $54.47 \pm 0.84^{\mathrm{a}}$ & $4.56 \pm 0.02^{\mathrm{a}}$ & $25.33 \pm 0.93^{\mathrm{b}}$ & $74.67 \pm 0.72^{\mathrm{b}}$ & $9.22 \pm 0.12^{\mathrm{c}}$ \\
AC-1C & $71.21 \pm 0.68^{\mathrm{b}}$ & $4.76 \pm 0.01^{\mathrm{a}}$ & $26.01 \pm 0.88^{\mathrm{b}}$ & $73.99 \pm 0.91^{\mathrm{b}}$ & $6.12 \pm 0.31^{\mathrm{b}}$ \\
AC-2C & $73.84 \pm 0.41^{\mathrm{b}}$ & $5.04 \pm 0.01^{\mathrm{b}}$ & $27.40 \pm 0.56^{\mathrm{c}}$ & $72.60 \pm 0.58^{\mathrm{b}}$ & $6.36 \pm 0.48^{\mathrm{b}}$ \\
Annealing & $53.08 \pm 0.32^{\mathrm{a}}$ & $4.76 \pm 0.02^{\mathrm{a}}$ & $24.24 \pm 0.83^{\mathrm{b}}$ & $75.76 \pm 0.82^{\mathrm{b}}$ & $8.89 \pm 0.52^{\mathrm{c}}$ \\
HMT & $70.94 \pm 0.41^{\mathrm{b}}$ & $4.50 \pm 0.01^{\mathrm{a}}$ & $16.01 \pm 0.57^{\mathrm{a}}$ & $83.99 \pm 0.61^{\mathrm{c}}$ & $2.53 \pm 0.71^{\mathrm{a}}$ \\
\hline
\end{tabular}

Different superscript letters within a row were significantly different at $\mathrm{p}<0.05$ level 
molecules and amylopectin to form short chain amylose fractions (Chen et al., 2018). In taro starch annealing, there was a re-association of amylose chains formed by the amylopectin breakdown (Wang et al., 2017). A study by Moore et al. (2015) showed that the increased amylose content and decreased reducing sugar level resulted in a positive effect on the formation of resistant starch (RS). Long-chain amylose was hydrolyzed either by heating, acid or enzymatically to form retrograded short chain amylose fractions (Chen et al., 2018).

The HMT and AC-1C, AC-2C starches showed a significant decrease in reducing sugar levels compared to the native taro starch $(\mathrm{p}<0.05)$ (Table 3$)$. Annealing treatment did not show a significant decrease in the reducing sugar level of taro starch than the others $(\mathrm{p}<0.05)$. The HMT showed the most significant decrease by $2.53 \%$ in the reducing sugar content of taro starch (Table 3). The decrease of reducing sugar levels in HMT and autoclaving-cooling cycle treatments was caused by the Maillard reaction. The Maillard reaction occurs due to the interaction between the amino acids and the reducing sugars at higher temperatures. Maillard reaction was influenced by high temperature, heating time and autoclaving-cooling cycles. The high reducing sugar levels inhibited the occurrence of the retrograded process, so it could reduce the RS level.

\section{Conclusion}

The autoclaving-cooling 2 cycles (AC-2C) changed the microstructure of MTS transforms into a very compact and dense, so it can be converted as resistant starch as a prebiotic source. Despite, MTS by HMT and annealing treatments showed similar microstructures with their native taro starch. AC-2C improved shear stress resistance, heat resistance and low retrogradation modified taro starch (MTS). The AC-2C treatment increased water binding capacity $(73.84 \%)$, solubility (44.58\%), and swelling power (16.71\%) of MTS. The water-binding capacity had a positive correlation with solubility and swelling power. The AC-2C treatment increased amylose content $(27.40 \%)$ and decreased reducing sugar level $(6.36 \%)$ of MTS, so it can encourage the formation of resistant starch to improve the prebiotic properties of taro starch. Modified taro starch $\mathrm{AC}-2 \mathrm{C}$ is the best compared to HMT and annealing based on microstructure and physicochemical characteristics.

\section{Conflict of Interest}

The authors declare no conflict of interest.

\section{Acknowledgments}

The authors would like to express their deepest gratitude to Research Center for Biology, Indonesian Institute of Sciences, and Science and Technology Postgraduate Scholarship from Ministry of Research and Technology in the Republic of Indonesia which had funded this research.

\section{References}

Abbas, K.A., Khalil, S.K. and Hussin, A.S.M. (2010). Modified starches and their usages in selected food products: a review study. Journal of Agricultural Science, 2(2), 90-100. https://doi.org/10.5539/ jas.v2n2p90

Aboubakar, Njintang, N.Y., Scher, J. and Mbofung, C.M.F. (2009). Texture, microstructure and physicochemical characteristics of taro (Colocasia esculenta) as influenced by cooking conditions. Journal of Food Engineering, 91(3), 373-379. https://doi.org/10.1016/j.jfoodeng.2008.09.030

Airul, A., Yusof, M.S.M., Jamil, M.S., Abdullah, A., Yusoff, S.F.M., Arip, M.N.M. and Lazim, A.M. (2014). Physicochemical characterization of starch extracted from Malaysian wild yam (Dioscorea hispida Dennst.). Emirates Journal Food Agriculture, 26(8), 652-658. https://doi.org/10.9755/ ejfa.v26i8.17098

Anderson, A.K., Guraya, H.S., James, C. and Salvaggio, L. (2002). Digestibility and pasting properties of rice starch heat-moisture treated at the melting temperature. Starch/Stärke, 54, 401-409. https:// doi.org/10.1002/1521-379X(200209)54:9<401::AID -STAR401>3.0.CO;2-Z

Arici, M., Yildirim, R.M., Ozülkü, G., Yasar, B. and Toker, O.S. (2016). Physicochemical and nutritional properties of taro (Colocasia esculenta L. Schott) flour as affected by drying temperature and air velocity. LWT - Food Science and Technology, 74, 434-440. https://doi.org/10.1016/j.lwt.2016.08.006

Ashwar, B.A., Gani, A., Wani, I.A., Shah, A., Masoodi, F.A. and Saxena, D.C. (2016). Production of resistant starch from rice by dual autoclaving retrogradation treatment: In-vitro digestibility, thermal and structural characterization. Food Hydrocolloids, 56, 108-117. https://doi.org/10.1016/ j.foodhyd.2015.12.004

Chen, Y.F., Singh, J. and Archer, R. (2018). Potato starch retrogradation in tuber: Structural changes and gastro-small intestinal digestion in vitro. Food Hydrocolloids, 84, 552-560. https://doi.org/10.1016/ j.foodhyd.2018.05.044

Cheng, K., Chen, S. and Yeh, A. (2019). 
Physicochemical properties and in vitro digestibility of rice after parboiling with heat moisture treatment. Journal of Cereal Science, 85, 98-104. https:// doi.org/10.1016/j.jcs.2018.11.016

Deka, D. and Sit, N. (2016). Dual modification of taro starch by microwave and other heat moisture treatments. International Journal of Biological Macromolecules, 92, 416-422. https:// doi.org/10.1016/j.ijbiomac.2016.07.040

Dundar, A.N. and Gocmen, D. (2013). Effects of autoclaving temperature and storing time on resistant starch formation and its functional and physicochemical properties. Carbohydrate Polymers, 97(2), 764-771. https://doi.org/10.1016/ j.carbpol.2013.04.083

Hazarika, B.J. and Sit, N. (2016). Effect of dual modification with hydroxypropylation and crosslinking on physicochemical properties of taro starch. Carbohydrate Polymers, 140, 269-278. https:// doi.org/10.1016/j.carbpol.2015.12.055

Jiang, Q., Gao, W., Li, X., Xia, Y., Wang, H., Wua, S. and Xiao, P. (2012). Characterizations of starches isolated from five different Dioscorea $L$. species. Food Hydrocolloids, 29(1), 35-41. https:// doi.org/10.1016/j.foodhyd.2012.01.011

Kaushal, P., Kumar, V. and Sharma, H.K. (2012). Comparative study of physicochemical, functional, antinutritional and pasting properties of taro (Colocasia esculenta), rice (Oryza sativa) flour, pigeon pea (Cajanus cajan) flour and their blends. LWT - Food Science and Technology, 48(1), 59-68. https://doi.org/10.1016/j.1wt.2012.02.028

Miller, G.L. (1959). Use of dinitrosalicylic acid reagent for determination of reducing sugar. Journal Analytical Chemistry, 31, 426-428. https:// doi.org/10.1021/ac60147a030

Moore, S.A., Ai, Y., Chang, F. and Jane, J. (2015). Effects of alpha-amylase reaction mechanisms on analysis of resistant starch contents. Carbohydrate Polymers, 115, 465-471. https://doi.org/10.1016/ j.carbpol.2014.09.014

Naidoo, K., Amonsou, E.O. and Oyeyinka, S.A. (2015). In vitro digestibility and some physicochemical properties of starch from wild and cultivated amadumbe corms. Carbohydrate Polymers, 125, 915. https://doi.org/10.1016/j.carbpol.2015.02.066

Setiarto, R.H.B., Jenie, B.S.L., Faridah, D.N., Saskiawan, I. and Sulistiani. (2018). Effect of lactic acid bacteria fermentation and autoclaving-cooling for resistant starch and prebiotic properties of modified taro flour. International Food Research Journal, 25(4), 1691-1697.
Shah, A., Masoodi, F.A., Gani, A. and Ashwar, B.A. (2016). In-vitro digestibility, rheology, structure, and functionality of RS3 from oat starch. Food Chemistry, 212, 749-758. https://doi.org/10.1016/ j.foodchem.2016.06.019

Sharlina, M.S.E., Yaacob, W.A., Lazim, A.M., Fazry, S., Lim, S.J., Abdullah, S., Noordin, A. and Kumaran, M. (2017). Physicochemical Properties of Starch from Dioscorea pyrifolia tubers. Food Chemistry, 220, 225-232. https://doi.org/10.1016/ j.foodchem.2016.09.196

Simsek, S. and El, S.N. (2015). In vitro starch digestibility, estimated glycemic index and antioxidant potential of taro (Colocasia esculenta $L$. Schott) corm. Food Chemistry, 168, 257-261. https:// doi.org/10.1016/j.foodchem.2014.07.052

Wang, S., Wang, J., Wang, S. and Wang, S. (2017). Annealing improves paste viscosity and stability of starch. Food Hydrocolloids, 62, 203-211. https:// doi.org/10.1016/j.foodhyd.2016.08.006

Wang, X., Reddy, C.K. and Xu, B. (2018). A systematic comparative study on morphological, crystallinity, pasting, thermal and functional characteristics of starches resources utilized in China. Food Chemistry, 259, 81-88. https://doi.org/10.1016/ j.foodchem.2018.03.121

Xu, M., Saleh, A.S.M., Gong, B., Li, B., Jing, L., Gou, M., Jiang, H. and Li, W. (2018). The effect of repeated versus continuous annealing on structural, physicochemical, and digestive properties of potato starch. Food Research International, 111, 324-333. https://doi.org/10.1016/j.foodres.2018.05.052

Yu, Z.Y., Jiang, S.W., Cai, J., Cao, X.M., Zheng, Z., Jiang, S.T., Wang, H.L. and Pan, L.J. (2018). Effect of high pressure homogenization $(\mathrm{HPH})$ on the rheological properties of taro (Colocasia esculenta (L). Schott) pulp. Innovative Food Science and Emerging Technologies, 50, 160-168. https:// doi.org/10.1016/j.ifset.2018.09.002

Zheng, B., Wang, H., Shang, W., Xie, F., Li, X., Chen, L. and Zhou, Z. (2018). Understanding the digestibility and nutritional functions of rice starch subjected to heat-moisture treatment. Journal of Functional Foods, 45, 165-172. https:// doi.org/10.1016/j.jff.2018.03.041 